NBER WORKING PAPER SERIES

KEYNESIAN ECONOMICS WITHOUT THE PHILLIPS CURVE

\author{
Roger E.A. Farmer \\ Giovanni Nicolò \\ Working Paper 23837 \\ http://www.nber.org/papers/w23837 \\ NATIONAL BUREAU OF ECONOMIC RESEARCH \\ 1050 Massachusetts Avenue \\ Cambridge, MA 02138 \\ September 2017
}

We would like to thank participants at the UCLA macro and international finance workshops. We have both benefited from conversations with Konstantin Platonov. The views expressed herein are those of the authors and do not necessarily reflect the views of the National Bureau of Economic Research.

NBER working papers are circulated for discussion and comment purposes. They have not been peer-reviewed or been subject to the review by the NBER Board of Directors that accompanies official NBER publications.

(C) 2017 by Roger E.A. Farmer and Giovanni Nicolò. All rights reserved. Short sections of text, not to exceed two paragraphs, may be quoted without explicit permission provided that full credit, including $\odot$ notice, is given to the source. 
Keynesian Economics without the Phillips Curve

Roger E.A. Farmer and Giovanni Nicolò

NBER Working Paper No. 23837

September 2017

JEL No. E0,E12,E52

\section{ABSTRACT}

We extend Farmer's (2012b) Monetary (FM) Model in three ways. First, we derive an analog of the Taylor Principle and we show that it fails in U.S. data. Second, we use the fact that the model displays dynamic indeterminacy to explain the real effects of nominal shocks. Third, we use the fact the model displays steady-state indeterminacy to explain the persistence of unemployment. We show that the FM model outperforms the NK model and we argue that its superior performance arises from the fact that the reduced form of the FM model is a VECM as opposed to a VAR.

Roger E.A. Farmer

UCLA

Department of Economics

Box 951477

Los Angeles, CA 90095-1477

and NBER

rfarmer@econ.ucla.edu

Giovanni Nicolò

UCLA

Department of Economics

Los Angeles, CA 90095-1477

gnicolo@ucla.edu 


\title{
Keynesian Economics Without the Phillips Curve
}

\author{
By Roger E.A. Farmer and Giovanni Nicolò*
}

\begin{abstract}
We extend Farmer's (2012b) Monetary (FM) Model in three ways. First, we derive an analog of the Taylor Principle and we show that it fails in U.S. data. Second, we use the fact that the model displays dynamic indeterminacy to explain the real effects of nominal shocks. Third, we use the fact the model displays steady-state indeterminacy to explain the persistence of unemployment. We show that the FM model outperforms the NK model and we argue that its superior performance arises from the fact that the reduced form of the FM model is a VECM as opposed to a VAR.
\end{abstract}

United States macroeconomic data are well described by co-integrated nonstationary time series (Nelson and Plosser, 1982). This is true, not just of data that are growing such as GDP, consumption and investment. It is also true of data that are predicted by economic theory to be stationary such as the unemployment rate, the output gap, the inflation rate and the money interest rate, (King et al., 1991; Beyer and Farmer, 2007). ${ }^{1}$

The dominant New Keynesian paradigm is a three-equation model that explains persistent high unemployment by positing that wages and prices are 'sticky' (Galí, 2008; Woodford, 2003). Sticky-price models have difficulty generating enough persistence to understand the near unit root in unemployment data, as do models of the monetary transmission mechanism that assume sticky information (Mankiw and Reis, 2007) or rational inattention, (Sims, 2001a). ${ }^{2}$

Farmer (2012b) provides an alternative explanation of persistent high unemployment that we refer to as the Farmer Monetary (FM) model. ${ }^{3}$ The FM model differs from the three-equation NK model by replacing the Phillips curve with the belief function (Farmer, 1993), a new fundamental that has the same methodological status as preferences and technology. In the FM model, search frictions

\footnotetext{
* Farmer: Department of Economics, UCLA, rfarmer@econ.ucla.edu. Nicolò: Department of Economics, UCLA, gnicolo@ucla.edu. We would like to thank participants at the UCLA macro and international finance workshops. We have both benefited from conversations with Konstantin Platonov.

${ }^{1} \mathrm{~A}$ bounded random variable, such as the unemployment rate, cannot be a random walk over its entire domain. We view the I(1) assumption to be an approximation that is approximately valid for finite periods of time.

${ }^{2}$ We prefer to avoid the assumption of menu costs (Mankiw, 1985) or price rigidity (Christiano et al., 2005; Smets and Wouters, 2007), because our reading of the evidence as surveyed by Klenow and Malin (2010), is that prices at the micro level are not sticky enough to explain the properties of monetary shocks in aggregate data. The approach we follow here generates permanent equilibrium movements in the unemployment rate that are consistent with a unit root, or near unit root, in U.S. unemployment data.

${ }^{3}$ Farmer and Konstantin Platonov (Farmer and Platonov, 2016) build on this idea to explain the relationship between the FM model and alternative interpretations of the textbook IS-LM model (Mankiw, 2015) on which modern New-Keynesian models are based.
} 
lead to the existence of multiple steady state equilibria, and the steady-state unemployment rate is determined by aggregate demand.

The FM model displays both static and dynamic indeterminacy. Static indeterminacy means there are many possible equilibrium steady-state unemployment rates. Dynamic indeterminacy means there are many dynamic equilibrium paths, all of which converge to a given steady state. We resolve both forms of indeterminacy with a belief function that pins down a unique rational expectations equilibrium.

The structural properties of the FM model translate into a critical property of its reduced form. Appealing to the Engle-Granger Representation Theorem (Engle and Granger, 1987), we show that the FM model's reduced form is a co-integrated Vector Error Correction Model (VECM). The inflation rate, the output gap, and the federal funds rate, are non-stationary but display a common stochastic trend. The fact that our model is described by a VECM, rather than a VAR, implies that it displays hysteresis. In the absence of stochastic shocks, the model's steady-state depends on initial conditions.

The FM model was introduced by Farmer (2012b) in a paper in which he discussed the limitations of the NK model and proposed the FM model as an alternative. Our paper extends his work in three directions. ${ }^{4}$

First, we study the role of monetary feedback rules in stabilizing inflation, the output gap and the unemployment rate in the FM model. ${ }^{5}$ It is well known that the NK model has a unique determinate steady state when the central bank reacts aggressively to stabilize inflation, a concept that Michael Woodford (2003) refers to as the Taylor principle. We develop the FM analog of the Taylor principle and we show that it does not hold in the U.S. data either before or after 1980 .

Second, we use the fact that our analog of the Taylor Principle fails to hold in the U.S. data to explain the observation that monetary shocks have real effects. Unlike the NK model, which assumes that prices are exogenously sticky, we explain the real effects of nominal shocks as an endogenous equilibrium response to nominal shocks which is enforced by the properties of the belief function.

Third, we exploit the property of static indeterminacy to explain why the unemployment rate has a (near) unit root, in U.S. data. Our model resolves both dynamic indeterminacy and static indeterminacy by introducing beliefs about future nominal income growth as a new fundamental. We assume that individuals form expectations about future nominal income growth and we model these expectations as a martingale as in Farmer (2012b).

\footnotetext{
${ }^{4}$ Related papers to our current work are those of Farmer (2012a,b), Plotnikov (2012, 2013) and Farmer and Platonov (2016). Farmer (2012b) develops the basic three-equation model that we work with here and he discusses the philosophy that distinguishes his approach from the NK model. Farmer (2012a) developed the labor market theory that accounts for persistent unemployment and Plotnikov (2013, 2012) adds investment and capital accumulation. Farmer and Platonov (2016) extend the theoretical model of Farmer (2012a) by adding money.

${ }^{5}$ Because there is a one-to-one mapping between the output gap and the difference of unemployment from its natural rate, we will move freely in our discussion between these two concepts.
} 


\section{Relationship with Previous Literature}

Our paper is connected with an empirical literature that studies the medium term persistence of business cycles. This includes the work of Robert King, Charles Plosser, James Stock and Mark Watson (1991), Diego Comin and Mark Gertler (2006), King and Watson (1994), and Andreas Beyer and Farmer (2007).

Importantly, this literature finds that the unemployment rate is highly persistent and one cannot reject the hypothesis that the unemployment rate is a random walk. Viewed through the lens of neoclassical or New Keynesian theoretical models, the persistence of the unemployment rate is a supply side phenomenon. Something must be changing in either technology or preferences to cause permanent changes in the natural rate of unemployment. ${ }^{6}$

The supply-side approach is not the only way to interpret the fact that unemployment is persistent. As Christopher Sims demonstrated in his seminal paper on Vector Autoregressions (Sims, 1980), rational expectations models are typically under-identified. ${ }^{7}$ That fact leads to an important question: Is the persistent slow-moving component of the unemployment rate caused by aggregate supply shocks, or is it caused by aggregate demand shocks? This paper is part of a growing literature that provides theory and evidence in favor of the demand-side explanation for the persistence of high unemployment following a recession. ${ }^{8}$

\section{The Structural Forms of the NK and FM Models}

In Section II we write down the two structural models that form the basis for our empirical estimates in Section VII. These models have two equations in common. One of these is a generalization of the NK IS curve that arises from the Euler equation of a representative agent. The other is a policy rule that describes how the Fed sets the fed funds rate. The two common equations of our study are described below. ${ }^{9}$

\footnotetext{
${ }^{6}$ This is the interpretation of Robert Gordon (Gordon, 2013), who argues that unemployment is nonstationary because the natural rate of unemployment is a random walk. Because the natural rate of unemployment is associated with the solution to a social planning optimum, if persistent unemployment were caused by a permanent increase in the natural rate of unemployment, high persistent unemployment would, at least to a first approximation, be socially optimal. That is possible, but in our view, implausible.

${ }^{7}$ Building on that idea, Beyer and Farmer (2004) provided an algorithm to construct families of models, all of which have the same likelihood in a given data set. Some of the models generated by their method lead to a unique determinate equilibrium; others lead to an indeterminate equilibrium driven by self-fulfilling beliefs. Both classes of theoretical models have the same likelihood.

${ }^{8}$ Lawrence Summers (Summers, 2014) has recently resurrected a term secular stagnation coined by Alvin Hansen (Hansen, 1939) to refer to the fact that the economy may be stuck in a period of permanent under-employment equilibrium and Gauti Eggertsson and Neil Mehrotra (Eggertsson and Mehrotra, 2014) have formalized Hansen's mechanism in an overlapping generations framework. My own previous work Farmer (2012a); Farmer and Platonov (2016) provides a complete internally consistent explanation of secular stagnation that is consistent with the fact that the stock market and the unemployment rate are cointegrated random walks (Farmer, 2013). Olivier Blanchard and Summers (Blanchard and Summers, $1986,1987)$ provided an alternative explanation.

${ }^{9}$ Our discussion in sections II and III closely follows Farmer (2012b).
} 


\section{A. Two Equations that the NK and FM Models Share in Common}

We assume the log of potential real GDP grows at a constant rate and we estimate this series by regressing the log of real GDP on a constant and a time trend. The residual series is our empirical analog of the output gap. The FM model implies that the output gap is non-stationary and cointegrated with the CPI inflation rate and the federal funds rate. The NK model implies that the output gap is stationary.

In Equations (1) and (2), $y_{t}$ is our constructed output gap measure, $R_{t}$ is the federal funds rate and $\pi_{t}$ is the CPI inflation rate. The term $z_{d, t}$ is a demand shock, $z_{R, t}$ is a policy shock and $z_{s, t}$ is a random variable that represents the Fed's estimate of potential GDP. ${ }^{10}$

$$
\begin{gathered}
a y_{t}-a \mathbb{E}_{t}\left(y_{t+1}\right)+\left[R_{t}-\mathbb{E}_{t}\left(\pi_{t+1}\right)\right] \\
\quad=\eta\left(a y_{t-1}-a y_{t}+\left[R_{t-1}-\pi_{t}\right]\right)+(1-\eta) \rho+z_{d, t} . \\
R_{t}=\left(1-\rho_{R}\right) \bar{r}+\rho_{R} R_{t-1}+\left(1-\rho_{R}\right)\left[\lambda \pi_{t}+\mu\left(y_{t}-z_{s, t}\right)\right]+z_{R, t} .
\end{gathered}
$$

Equation (1) is a generalization of the dynamic IS curve that appears in standard representations of the NK model. In the special case when $\eta=1$ this equation can be derived from the Euler equation of a representative agent. ${ }^{11} \mathrm{An}$ equation of this form for the general case when $\eta \neq 1$ can be derived from a heterogeneous agent model (Farmer, 2016) where the lagged real interest rate captures the dynamics of borrowing and lending between patient and impatient groups of people. In the case when $\eta=1$, the parameter $a$ is the inverse of the intertemporal elasticity of substitution and $\rho$ is the time preference rate.

Equation (2) is a Taylor Rule (Taylor, 1999) that represents the response of the monetary authority to the lagged nominal interest rate, the inflation rate and the output gap. The monetary policy shock, $z_{R, t}$, denotes innovations to the nominal interest rate caused by unpredictable actions of the monetary authority. The parameters $\rho_{R}, \lambda$ and $\mu$ are policy elasticities of the fed funds rate with respect to the lagged fed funds rate, the inflation rate and the output gap.

\section{B. Two Equations that Differentiate the Two Models}

The third equation of the NK model is given by

$$
\pi_{t}=\beta \mathbb{E}_{t}\left[\pi_{t+1}\right]+\phi\left(y_{t}-z_{s, t}\right) .
$$

\footnotetext{
${ }^{10}$ More precisely, $z_{s, t}$ is the Fed's estimate of the deviation of the log of potential GDP from a linear trend.

${ }^{11}$ See for example Galí (2008), or Woodford (2003).
} 
Here, $\beta$ is the discount rate of the representative person and $\phi$ is a compound parameter that depends on the frequency of price adjustment. Since $\beta$ is expected to be close to one, we will impose the restriction $\beta=1$ when discussing the theoretical properties of the model. This restriction implies that the long-run Phillips curve is vertical. If instead, $\beta<1$, the NK model has an upward sloping long-run Phillips curve in inflation-output gap space. An extensive literature derives the NK Phillips curve from first principles, see for example Galí (2008), based on the assumption that frictions of one kind or another prevent firms from quickly changing prices in response to changes in demand or supply shocks.

In contrast to the NK Phillips curve, the FM model is closed by a belief function (Farmer, 1993). The functional form for the belief function that we use in this study is described by Equation (3.b),

$$
\mathbb{E}_{t}\left[x_{t+1}\right]=x_{t},
$$

where $x_{t} \equiv \pi_{t}+\left(y_{t}-y_{t-1}\right)$ is the growth rate of nominal GDP.

The belief function is a mapping from current and past observable variables to probability distributions over future economic variables. In the functional form we use here, it asserts that agents' forecast about future nominal GDP growth will equal current nominal GDP growth; that is, nominal GDP growth is a martingale. Farmer (2012b) has shown that this specification of beliefs is a special case of adaptive expectations in which the weight on current observations of GDP growth is equal to $1 .^{12}$

In the FM model, the monetary authority chooses whether changes in the current growth rate of nominal GDP will cause changes in the expected inflation rate or in the output gap. Importantly, these changes will be permanent. The belief function, interacting with the policy rule, selects how demand and supply shocks are distributed between permanent changes to the output gap, and permanent changes to the expected inflation rate.

\section{The Steady-State Properties of the Two Models}

In this section we compare the theoretical properties of the non-stochastic steady-state equilibria of the NK and FM models. The NK model has a unique steady-state equilibrium. The FM model, in contrast, has a continuum of nonstochastic steady-state equilibria. Which of these equilibria the economy converges to depends on the initial condition of a system of dynamic equations. This property is known as hysteresis. ${ }^{13}$

Rather than treat the multiplicity of steady state equilibria as a deficiency, as is often the case in economics, we follow Farmer (1993) by defining a new fundamental, the belief function. When the model is closed in this way, equilibrium

\footnotetext{
${ }^{12}$ Farmer (2012b) allowed for a more general specification of adaptive expectations and he found that the data favor the special case we use here.

${ }^{13}$ This analysis reproduces the discussion from Farmer $(2012 b)$ and we include it here for completeness.
} 
uniqueness is restored and every sequence of shocks is associated with a unique sequence of values for the three endogenous variables.

We begin by shutting down shocks and describing the theoretical properties of the steady-state of the NK model. The values of the steady-state inflation rate, interest rate and output gap in the NK model are given by the following equations

$$
\bar{\pi}=\frac{\phi(\bar{r}-\rho)}{\phi(1-\lambda)-\mu(1-\beta)}, \quad \bar{R}=\rho+\bar{\pi}, \quad \bar{y}=\bar{\pi} \frac{(1-\beta)}{\phi} .
$$

When $\beta<1$, the long-run Phillips curve, in output gap-inflation space, is upward sloping. As $\beta$ approaches 1, the slope of the long-run Phillips curve becomes vertical and these equations simplify as follows,

$$
\bar{\pi}=\frac{(\bar{r}-\rho)}{(1-\lambda)}, \quad \bar{R}=\rho+\bar{\pi}, \quad \bar{y}=0 .
$$

For this important special case, the steady state of the NK model is defined by Equations (4).

Contrast this with the steady state of FM model, which has only two steady state equations to solve for three steady state variables. These are given by the steady state version of the IS curve, Equation (1), and the steady state version of the Taylor Rule, Equation (2).

The FM model is closed, not by a Phillips Curve, but by the belief function. In the specific implementation of the belief function in this paper we assume that beliefs about future nominal income growth follow a martingale. This equation does not provide any additional information about the non-stochastic steady state of the model because the same variable, steady-state nominal income growth, appears on both sides of the equation.

Solving the steady-state versions of equations (1) and (2) for $\bar{\pi}$ and $\bar{R}$ as a function of $\bar{y}$ delivers two equations to determine the three variables, $\bar{\pi}, \bar{R}$ and $\bar{y}$.

$$
\bar{\pi}=\frac{(\bar{r}-\rho)}{(1-\lambda)}+\frac{\mu}{(1-\lambda)} \bar{y}, \quad \bar{R}=\rho+\bar{\pi} .
$$

The fact that there are only two equations to determine three variables implies that the steady-state of the FM model is under determined. We refer to this property as static indeterminacy. Static indeterminacy is a source of endogenous persistence that enables the FM model to match the high persistence of the unemployment rate in data and it implies that the reduced form representation of the FM model is a VECM, as opposed to a VAR.

An implication of the static indeterminacy of the model is that policies that affect aggregate demand have permanent long-run effects on the output gap and the unemployment rate. In contrast, the NK model incorporates the Natural Rate Hypothesis, a feature which implies that demand management policy cannot affect 
real economic activity in the long-run.

\section{The FM Analog of the Taylor Principle: A Simple Case}

In this section we discuss the NK Taylor Principle and we derive an analog of this principle for the FM model. For both the NK and FM models we study the special case of $\rho_{R}=0$, and $\eta=0$. The first of these restrictions sets the response of the Fed to the lagged interest rate to zero. The second restricts the IS curve to the representative agent case. These restrictions allow us to generate, and compare, analytical expressions for the Taylor Principle in both models.

The special cases of Equations (1) and (2) are given by

$$
a y_{t}=a E_{t}\left(y_{t+1}\right)-\left(R_{t}-\mathbb{E}_{t}\left(\pi_{t+1}\right)\right)+\rho+z_{d, t},
$$

and

$$
R_{t}=\bar{r}+\lambda \pi_{t}+\mu\left(y_{t}-z_{s, t}\right)+z_{R, t} .
$$

The Taylor Principle directs the central bank to increase the federal funds rate by more than one-for-one in response to an increase in the inflation rate. When the Taylor Principle is satisfied, the dynamic equilibrium of the NK model is locally unique. When that property holds, we say that the unique steady state is locally determinate (Clarida et al., 1999).

When the central bank responds only to the inflation rate, the Taylor principle is sufficient to guarantee local determinacy. When the central bank responds to the output gap as well as to the inflation rate, a sufficient condition for the NK model to be locally determinate is that

$$
\left|\lambda+\frac{1-\beta}{\phi} \mu\right|>1
$$

For the important special case of $\beta=1$ this reduces to the familiar form of the Taylor principle (Woodford, 2003).

In Appendix A we derive this result analytically and we compare it with the dynamic properties of the FM model. There we establish that for the special case of logarithmic preferences, that is when $a=1$, a sufficient condition for local determinacy in the FM model is,

$$
\left|\frac{\lambda}{\lambda-\mu}\right|>1
$$

This is our FM analog of the Taylor principle. In the usual case when $\lambda$ and $\mu$ are positive, it requires the interest-rate response of the central bank to changes in inflation to be greater than the output-gap response. When this condition holds, each element of the set of steady state equilibria of the model is dynamically 
determinate.

\section{The FM Analog of the Taylor Principle: The General Case}

When the representative agent has $C R A$ preferences with $a \neq 1$, the FM version of the Taylor principle is more complicated and we are unable to find an analytic expression except in the case when $\lambda=\mu{ }^{14}$ In this special case, the Taylor Principle fails whenever

$$
a<1+\frac{\lambda}{2}
$$

Although the parameter restriction, $\lambda=\mu$, is unlikely to hold in practice, it does give us an indication of whether or not the FM Taylor principle is likely to hold outside of the case of logarithmic preferences. The answer to that question is no. Consider, as an example, the special case when $\lambda=\mu=0.7$. For this parametrization, the determinacy condition fails when $a$ is larger than 1.35. Since estimates of $a$ in data are typically larger than 2 , it seems likely that failure of the Taylor Principle will be the normal case. Indeed, that conjecture is verified by our empirical estimates. When we allow $\lambda$ and $\mu$ to differ and we estimate them using Bayesian techniques, our estimated model displays dynamic indeterminacy for positive values of $a$ that are greater than, but much closer to, one.

In Figure 1 we set three key parameters to their estimated values of $\eta=0.89$, $\rho=0.021$, and $\rho_{R}=0.98$ and we plot the roots of the system as functions of the risk-aversion parameter $a$. This matrix always has a unit root and a root of zero. ${ }^{15}$ The determinacy condition requires that the remaining two roots must both be greater than one in absolute value. The figure shows that for our estimated parameter values, one root falls below unity in absolute value for values of $a$ greater than 1.004 .

We conclude from our analysis of the roots that plausible parametrizations of the FM model display dynamic as well as static indeterminacy and that conclusion is confirmed by our empirical estimates, described in Section VII, in which we freely estimate $a$ to be equal to 3.8 .

The conjunction of static and dynamic indeterminacy provide two sources of endogenous persistence. Static indeterminacy implies that the output gap contains an I(1) component. Instead of converging to a point in interest-rate-inflationoutput gap space, the data converge to a one-dimensional linear manifold. Dynamic indeterminacy implies that the fed funds rate, the inflation rate and the unemployment rate display persistent deviations from this manifold.

The fact that the model displays dynamic indeterminacy allows us to explain why prices appear to move slowly in data. In response to an increase in the fed

\footnotetext{
${ }^{14}$ We provide a derivation of the analytic result in Appendix B.

${ }^{15}$ Since the unit root and the root of zero do not depend on the parameter values, we do not display them in Figure 1.
} 


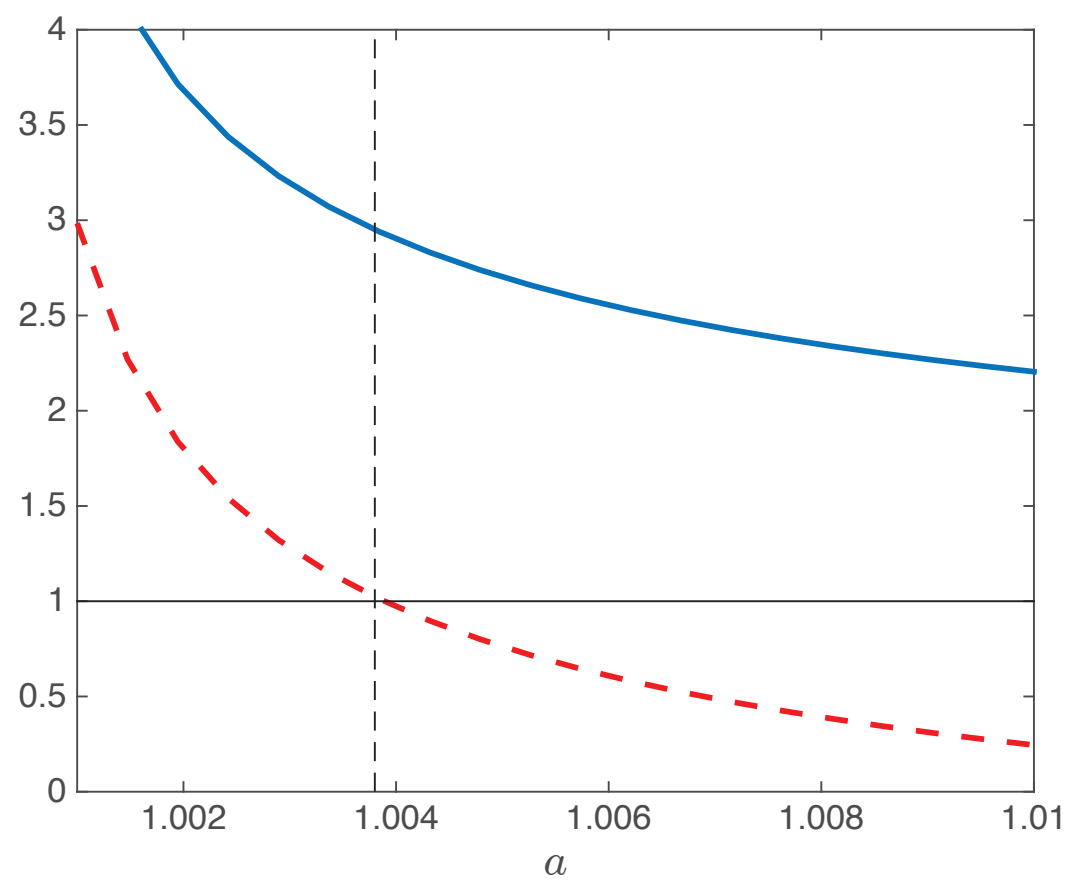

Figure 1. : Characteristic roots as a function of $a: \lambda=0.76, \mu=0.75$

funds rate it is the output gap, not the inflation rate, that bears the burden of adjustment. Prices are not sticky in the sense that there is a cost or barrier to price adjustment. They are sticky because people believe, correctly, that future prices will validate their decision to demand fewer goods and services in response to an increase in the money interest rate.

\section{Solving the NK and FM Models}

\section{A. Finding the Reduced forms of the Two Models}

Sims (2001b) showed how to write a structural DSGE model in the form

$$
\Gamma_{0} X_{t}=C+\Gamma_{1} X_{t-1}+\Psi \varepsilon_{t}+\Pi \eta_{t}
$$

where $X_{t} \in \mathbb{R}^{n}$ is a vector of variables that may or may not be observable. Using the following definitions, the NK and FM models can both be expressed in this 
way, ${ }^{16}$

$$
X_{t}=\left[\begin{array}{c}
y_{t} \\
\pi_{t} \\
R_{t} \\
\mathbb{E}_{t}\left(y_{t+1}\right) \\
\mathbb{E}_{t}\left(\pi_{t+1}\right) \\
z_{d, t} \\
z_{s, t}
\end{array}\right], \quad \varepsilon_{t}=\left[\begin{array}{c}
z_{R, t} \\
\varepsilon_{d, t} \\
\varepsilon_{s, t}
\end{array}\right], \quad \eta_{t}=\left[\begin{array}{c}
y_{t}-\mathbb{E}_{t-1}\left(y_{t}\right) \\
\pi_{t}-\mathbb{E}_{t-1}\left(\pi_{t}\right)
\end{array}\right] .
$$

The shocks $\varepsilon_{t}$ are called fundamental and the shocks $\eta_{t}$ are non-fundamental. By exploiting a property of the generalized Schur decomposition (Gantmacher, 2000) Sims provided an algorithm, GENSYS, that determines if there exists a VAR of the form

$$
X_{t}=\hat{C}+G_{0} X_{t-1}+G_{1} \varepsilon_{t}
$$

such that all stochastic sequences $\left\{X_{t}\right\}_{t=1}^{\infty}$ generated by this equation also satisfy the structural model, Equation (9). ${ }^{17}$ To guarantee that solutions remain bounded, all of the eigenvalues of $G_{0}$ must lie inside the unit circle. When a solution of this kind exists, we refer to it as a reduced form of (9).

GENSYS reports on whether a reduced form exists and, if it exists, whether it is unique. The algorithm eliminates unstable generalized eigenvalues of the matrices $\left\{\Gamma_{0}, \Gamma_{1}\right\}$ by finding expressions for the non-fundamental shocks, $\eta_{t}$, as functions of the fundamental shocks, $\varepsilon_{t}$. When there are too few unstable generalized eigenvalues, there are many candidate reduced forms.

For the case of multiple candidate reduced forms, Farmer et al. (2015) show how to redefine a subset of the non-fundamental shocks as new fundamental shocks. For example, if the model has one degree of indeterminacy, one may define a vector of expanded fundamental shocks, $\hat{\varepsilon}_{t}$,

$$
\hat{\varepsilon}_{t} \equiv\left[\begin{array}{c}
\varepsilon_{t} \\
\eta_{t}^{1}
\end{array}\right]
$$

The parameters of the variance-covariance matrix of expanded fundamental shocks are fundamentals of the model that may be calibrated or estimated in the same way as the parameters of the utility function or the production function.

We assume that prices are subject to an independent sunspot shock that is uncorrelated with the innovations to the other three fundamental shocks. This assumption forces shocks to the policy rule to be transmitted contemporaneously to the output gap and it enables the FM model to explain a monetary transmission

\footnotetext{
${ }^{16}$ We assume, in our estimation, that $z_{d, t}$ and $z_{s, t}$ may be auto-correlated but we restrict $z_{R, t}$ to be i.i.d. For this reason, the innovations to $z_{d, t}$ and $z_{s, t}$ appear in $\varepsilon_{t}$ along with the realized value of $z_{R, t}$.

${ }^{17}$ The generalized Schur decomposition exploits the properties of the generalized eigenvalues of the matrices $\left\{\Gamma_{0}, \Gamma_{1}\right\}$.
} 
mechanism in which nominal shocks are transmitted to prices slowly over time.

To solve and estimate both the NK and FM models, we use an implementation of GENSYS, (Sims, 2001b) programmed in DYNARE (Adjemian et al., 2011), to find the reduced form associated with any given point in the parameter space. We use the Kalman filter to generate the likelihood function and a Markov Chain Monte Carlo algorithm to explore the posterior.

\section{B. An Important Implication of the Engle-Granger Representation Theorem}

The reduced form of both the NK and FM models is a Vector Autoregression with the form of Equation (11). We reproduce that equation below.

$$
X_{t}=\hat{C}+G_{0} X_{t-1}+G_{1} \varepsilon_{t} .
$$

Robert Engle and Clive Granger (1987) showed how to rewrite a Vector-Autoregression in the equivalent form

$$
\Delta X_{t}=\hat{C}+\hat{\Pi} X_{t-1}+G_{1} \varepsilon_{t}
$$

where $X_{t} \in \mathbb{R}^{n}$. If the matrix $\hat{\Pi}$ has rank $n$, this system of equations has a well defined non-stochastic steady state, $\bar{X}$, defined by shutting down the shocks and setting $X_{t}=\bar{X}$ for all $t . \bar{X}$ is defined by the expression,

$$
\bar{X}=-\hat{\Pi}^{-1} \hat{C} .
$$

When $\hat{\Pi}$ has rank $r<n$, it can be written as the product of an $n \times r$ matrix $\alpha$ and an $r \times n$ matrix $\beta^{\top}$,

$$
\hat{\Pi}=\alpha \beta^{\top} .
$$

The rows of $\alpha$ are referred to as loading factors, and the columns of $\beta$ are called co-integrating vectors. ${ }^{18}$

When $\hat{\Pi}$ has reduced rank there is no steady state and in the absence of stochastic shocks the sequence $X_{t}$ will converge to a point on an $n-r$ dimensional linear subspace of $\mathbb{R}^{n}$ that depends on the initial condition $X_{0}$.

The NK model has a unique steady state and its Engle-Granger representation leads to a matrix $\hat{\Pi}$ with full rank. In contrast, the FM model has multiple steady states and its Engle-Granger representation leads to a matrix $\hat{\Pi}$ with reduced rank. It follows that the reduced form of the FM model is a VECM as opposed to a VAR.

\footnotetext{
${ }^{18}$ The co-integrating vectors are not uniquely defined; they are linear combinations of the steady state equations of the non-stochastic model.
} 


\section{Estimating the Parameters of the NK and FM Models}

In this section we estimate the NK and FM models. Both models share equations (1) and (2) in common. We reproduce these equations below for completeness.

$$
\begin{array}{r}
a y_{t}-a \mathbb{E}_{t}\left(y_{t+1}\right)+\left[R_{t}-\mathbb{E}_{t}\left(\pi_{t+1}\right)\right] \\
=\eta\left(a y_{t-1}-a y_{t}+\left[R_{t-1}-\pi_{t}\right]\right)+(1-\eta) \rho+z_{d, t} . \\
R_{t}=\left(1-\rho_{R}\right) \bar{r}+\rho_{R} R_{t-1}+\left(1-\rho_{R}\right)\left[\lambda \pi_{t}+\mu\left(y_{t}-z_{s, t}\right)\right]+z_{R, t} .
\end{array}
$$

For the NK model these equations are supplemented by the Phillips curve, Equation (3.a),

$$
\pi_{t}=\beta \mathbb{E}_{t}\left[\pi_{t+1}\right]+\phi\left(y_{t}-z_{s, t}\right),
$$

and for the FM model they are supplemented by the belief function, Equation (3.b),

$$
\mathbb{E}_{t}\left[x_{t+1}\right]=x_{t} .
$$

We assume in both models that the demand and supply shocks follow autoregressive processes that we model with equations (16) and (17),

$$
\begin{aligned}
& z_{d, t}=\rho_{d} z_{d, t-1}+\varepsilon_{d, t}, \\
& z_{s, t}=\rho_{s} z_{s, t-1}+\varepsilon_{s, t} .
\end{aligned}
$$

Figure 2 plots the data that we use to compare the models. We use three time series for the U.S. over the period from 1954Q3 to 2007Q4: the effective Federal Funds Rate, the CPI inflation rate and the percentage deviation of real GDP from a linear trend.

To estimate the models, we used a Markov-Chain Monte-Carlo algorithm, implemented in DYNARE (Adjemian et al., 2011). Formal tests reject the null of parameter constancy over the entire period. Beyer and Farmer (2007) find evidence of a break in 1980 and we know from the Federal Reserve Bank's own website (of San Francisco, January 2003) that the Fed pursued a monetary targeting strategy from 1979Q3 through 1982Q3. For this reason, and in line with previous studies (Clarida et al., 2000; Lubik and Schorfheide, 2004; Primiceri, 2005), we estimated both models over two separate sub-periods.

Our first sub-period runs from 1954Q3 through 1979Q2. The beginning date is one year after the end of the Korean war; the ending date coincides with the appointment of Paul Volcker as Chairman of the Federal Reserve Board. We 


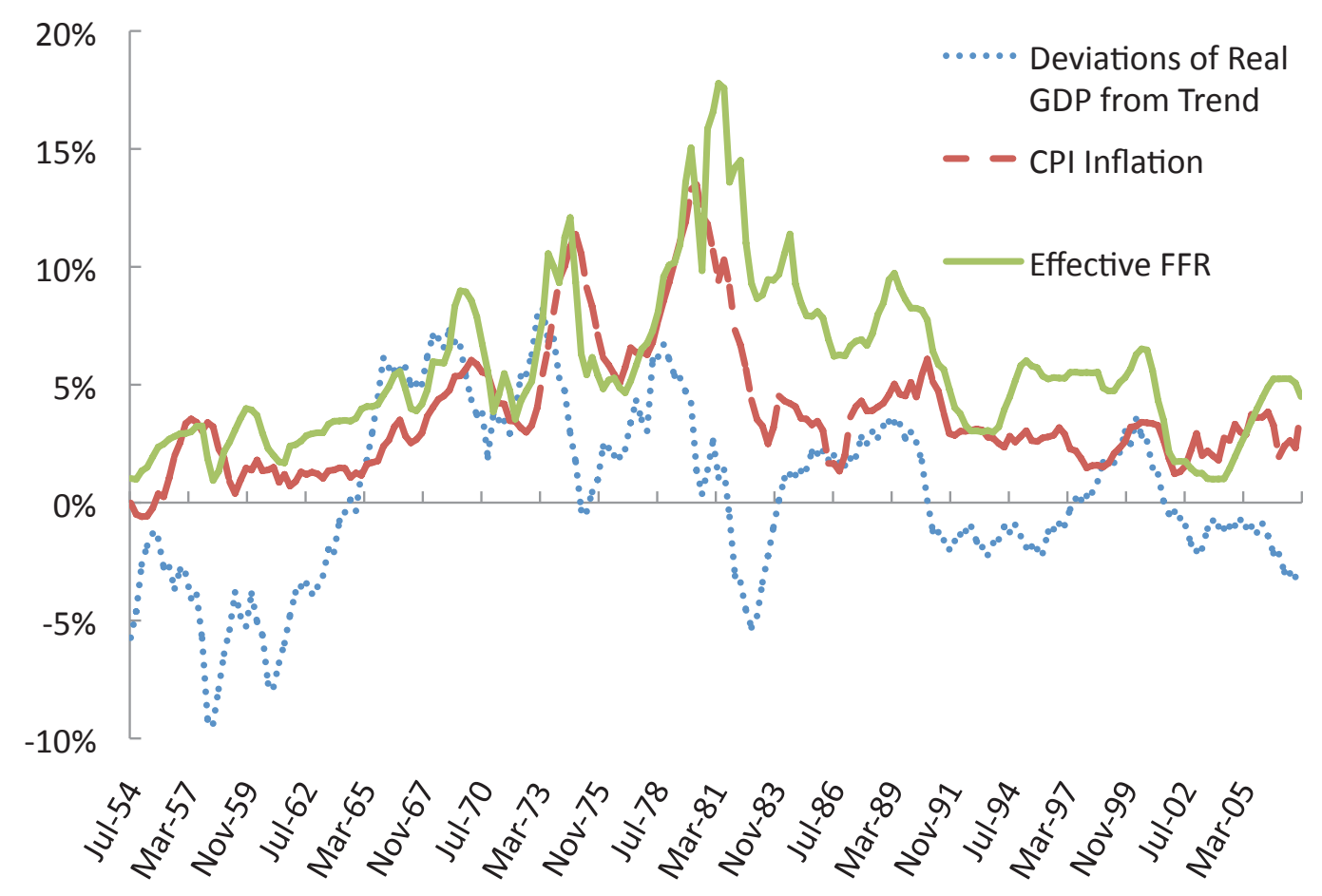

Figure 2. : U.S. data 
excluded the period from 1979Q3 through 1982Q4 because, over that period, the Fed was explicitly targeting the growth rate of the money supply. In 1983Q1, it reverted to an interest rate rule.

Our second sub-period runs from 1983Q1 to 2007Q4. We ended the sample with the Great Recession to avoid potential issues arising from the fact that the federal funds rate hit a lower bound in the beginning of 2009 and our linear approximation is unlikely to fare well for that period.

\begin{tabular}{|c|c|c|c|c|c|}
\hline Name & Range & Density & Mean & Std. Dev. & $90 \%$ interval \\
\hline$a$ & $R^{+}$ & Gamma & 3.5 & 0.50 & {$[2.67,4.32]$} \\
\hline$\rho$ & $R^{+}$ & Gamma & 0.02 & 0.005 & {$[0.012,0.028]$} \\
\hline$\eta$ & {$[0,1)$} & Beta & 0.85 & 0.10 & {$[0.65,0.97]$} \\
\hline $\bar{r}$ & $R^{+}$ & Uniform & 0.05 & 0.029 & {$[0.005,0.095]$} \\
\hline$\rho_{R}$ & {$[0,1)$} & Beta & 0.85 & 0.10 & {$[0.65,0.97]$} \\
\hline$\mu$ & $R^{+}$ & Gamma & 0.70 & 0.20 & {$[0.41,1.06]$} \\
\hline$\rho_{d}$ & {$[0,1)$} & Beta & 0.80 & 0.05 & {$[0.71,0.87]$} \\
\hline$\rho_{s}$ & {$[0,1)$} & Beta & 0.90 & 0.05 & {$[0.81,0.97]$} \\
\hline$\sigma_{R}$ & $R^{+}$ & Inverse Gamma & 0.01 & 0.003 & {$[0.005,0.015]$} \\
\hline$\sigma_{d}$ & $R^{+}$ & Inverse Gamma & 0.01 & 0.003 & {$[0.005,0.015]$} \\
\hline$\sigma_{\zeta}$ & $R^{+}$ & Inverse Gamma & 0.005 & 0.003 & {$[0.002,0.010]$} \\
\hline$\rho_{d s}$ & {$[-1,1]$} & Uniform & 0 & 0.58 & {$[-0.9,0.9]$} \\
\hline$\rho_{d R}$ & {$[-1,1]$} & Uniform & 0 & 0.58 & {$[-0.9,0.9]$} \\
\hline$\rho_{s R}$ & {$[-1,1]$} & Uniform & 0 & 0.58 & {$[-0.9,0.9]$} \\
\hline $\bar{\beta}$ & {$[0,1)$} & Beta & 0.97 & 0.01 & {$[0.95,0.98]$} \\
\hline$\phi$ & $R^{+}$ & Gamma & 0.50 & 0.20 & {$[0.22,0.87]$} \\
\hline
\end{tabular}

\begin{tabular}{|c|c|c|c|c|c|}
\hline \multicolumn{6}{|c|}{ Table 1.B: Prior distribution for each sample period } \\
\hline Name & Range & Density & Mean & Std. Dev. & $90 \%$ interval \\
\hline Pre-Volcker & & & & & \\
\hline$\lambda$ & $R^{+}$ & Gamma & 0.9 & 0.50 & {$[0.26,1.85]$} \\
\hline$\sigma_{s}$ & $R^{+}$ & Inverse Gamma & 0.1 & 0.03 & {$[0.06,0.15]$} \\
\hline Post-Volcker & & & & & \\
\hline$\lambda$ & $R^{+}$ & Gamma & 1.1 & 0.50 & {$[0.42,2.02]$} \\
\hline$\sigma_{s}$ & $R^{+}$ & Inverse Gamma & 0.01 & 0.005 & {$[0.005,0.019]$} \\
\hline
\end{tabular}

Table 1.A summarizes the prior parameter distributions that we used in this procedure for those parameters that were the same in both sub-samples. The table reports the prior shape, mean, standard deviation and $90 \%$ probability interval. Table 1.B presents the prior distributions for parameters that were different in the two subsamples. These were $\lambda$, the policy coefficient for the interest rate response to the inflation rate, and $\sigma_{s}$, the standard deviation of the supply shock. 
We set $\lambda=0.9$ in the first sub-period and $\lambda=1.1$ in the second. We chose these values because Lubik and Schorfheide (2004) found that policy was indeterminate in the first period and determinate in the second. These choices ensure that our priors are consistent with these differences in regimes.

We set the standard deviation of $\sigma_{s}$ to 0.1 in the pre-Volcker sample and 0.01 in the post-Volcker sample. We made this choice because earlier studies (Primiceri, 2005; Sims and Zha, 2006) found that the variance of shocks was higher in the post-Volcker sample, consistent with the fact that there were two major oil-price shocks in this period.

We restricted the parameters of the policy rule to lie in the indeterminacy region for the pre-Volcker period and the determinacy region for the post-Volcker. Those restrictions are consistent with Lubik and Schorfheide (2004) who estimated a NK model, pre- and post-Volcker, and found that the NK model was best described by an indeterminate equilibrium in the first sub-period. Our priors for $a, \lambda$ and $\mu$ place the FM model in the indeterminacy region of the parameter space for both sub-samples.

To identify the NK model in the pre-Volcker period, and for the FM model in both sub-periods, we chose a pre-determined price equilibrium. We selected that equilibrium by choosing the forecast error

$$
\eta_{t}^{\pi} \equiv \pi_{t}-\mathbb{E}_{t-1}\left[\pi_{t}\right]
$$

as a new fundamental shock and we identified the variance covariance matrix of shocks by setting the covariance of $\eta_{t}^{\pi}$ with the other fundamental shocks, to zero.

The results of our estimates are reported in Tables 2, 3 and 4. Table 2 reports the logarithm of the marginal data densities and the corresponding posterior model probabilities under the assumption that each model has equal prior probability. These were computed using the modified harmonic mean estimator proposed by Geweke (1999). In Tables 3 and 4 we present parameter estimates for the pre-Volcker period (1954Q3-1979Q2) and the post-Volcker period, (1983Q12007).

\begin{tabular}{lccc}
\hline & Table 2: Model comparison & & \\
\hline \hline Pre-Volcker (54Q3-79Q2) & FM model & NK model \\
& Log data density & 1023.24 & 1017.26 \\
& Posterior Model Prob (\%) & 100 & 0 \\
\hline Post-Volcker (83Q1-07Q4) & Log data density & 1136.22 & 1121.42 \\
& Posterior Model Prob (\%) & 100 & 0 \\
\hline \hline
\end{tabular}

We find that, in both subsamples, the posterior model probability is $100 \%$. In 
words, the data strongly favor the VECM representation over the VAR.

\begin{tabular}{|c|c|c|c|c|}
\hline \multicolumn{5}{|c|}{ Table 3: Posterior estimates, Pre-Volcker (54Q3-79Q2) } \\
\hline \multicolumn{4}{|c|}{ FM model } & NK model \\
\hline & Mean & $90 \%$ probability interval & Mean & $90 \%$ probability interval \\
\hline$a$ & 3.80 & {$[3.11,4.46]$} & 3.70 & {$[2.91,4.49]$} \\
\hline$\rho$ & 0.020 & {$[0.012,0.027]$} & 0.017 & {$[0.010,0.023]$} \\
\hline$\eta$ & 0.87 & {$[0.83,0.92]$} & 0.76 & {$[0.63,0.89]$} \\
\hline $\bar{r}$ & 0.051 & {$[0.014,0.093]$} & 0.043 & {$[0.002,0.079]$} \\
\hline$\rho_{R}$ & 0.94 & {$[0.91,0.97]$} & 0.98 & {$[0.97,0.99]$} \\
\hline$\lambda$ & 0.80 & {$[0.22,1.34]$} & 0.45 & {$[0.17,0.73]$} \\
\hline$\mu$ & 0.74 & {$[0.44,1.03]$} & 0.56 & {$[0.28,0.84]$} \\
\hline$\rho_{d}$ & 0.76 & {$[0.69,0.83]$} & 0.80 & {$[0.72,0.88]$} \\
\hline$\rho_{s}$ & 0.95 & {$[0.92,0.98]$} & 0.78 & {$[0.71,0.86]$} \\
\hline$\sigma_{R}$ & 0.007 & {$[0.006,0.008]$} & 0.008 & {$[0.007,0.009]$} \\
\hline$\sigma_{d}$ & 0.011 & {$[0.009,0.013]$} & 0.011 & {$[0.007,0.014]$} \\
\hline$\sigma_{s}$ & 0.097 & {$[0.059,0.133]$} & 0.059 & {$[0.043,0.073]$} \\
\hline$\sigma_{\zeta}$ & 0.003 & {$[0.003,0.004]$} & 0.003 & {$[0.002,0.004]$} \\
\hline$\rho_{R d}$ & 0.79 & {$[0.64,0.95]$} & -0.06 & {$[-0.30,0.17]$} \\
\hline$\rho_{R s}$ & -0.53 & {$[-0.80,-0.26]$} & 0.59 & {$[0.43,0.76]$} \\
\hline$\rho_{d s}$ & -0.79 & {$[-0.94,-0.65]$} & 0.11 & {$[-0.22,0.47]$} \\
\hline$\beta$ & $\mathrm{n} / \mathrm{a}$ & $\mathrm{n} / \mathrm{a}$ & 0.98 & {$[0.97,0.99]$} \\
\hline$\phi$ & $\mathrm{n} / \mathrm{a}$ & $\mathrm{n} / \mathrm{a}$ & 0.07 & {$[0.04,0.09]$} \\
\hline
\end{tabular}

The dynamic properties of the FM model depend on the value of the parameter a. We tried restricting this parameter to be less than 1, a restriction that places the FM model in the determinacy region of the parameter space. We found that the posterior for a model that imposes this restriction was clearly dominated by allowing $a$ to lie in the indeterminacy region. In both the FM and NK cases, we used the approach of Farmer et al. (2015) which allows the econometrician to use standard software packages to estimate indeterminate models.

Table 3, reports the estimated parameters of both the FM and NK models. For both of these models, the parameter estimates place the model in the indeterminacy region and, in both cases, we resolved the indeterminacy by selecting an equilibrium in which the co-variance parameters of shocks to the inflation surprise with the other fundamentals shocks was set to zero.

Table 4 reports the posterior estimates for the post-Volcker period (1983Q12007Q4). For this sample period, the FM estimates place the model in the region of dynamic indeterminacy and, once again, we resolved the indeterminacy by selecting a pre-determined price equilibrium. In contrast, the posterior means of the NK model satisfy the Taylor Principle, thus guaranteeing that the equilibrium of NK model is locally unique. 


\begin{tabular}{|c|c|c|c|c|}
\hline \multicolumn{5}{|c|}{ Table 4: Posterior estimates, Post-Volcker (83Q1-07Q4) } \\
\hline \multicolumn{4}{|c|}{ FM model } & \multirow{2}{*}{$\begin{array}{c}\text { NK model } \\
90 \% \text { probability interval }\end{array}$} \\
\hline & Mean & $90 \%$ probability interval & Mean & \\
\hline$a$ & 4.23 & {$[3.46,4.99]$} & 3.62 & {$[2.87,4.35]$} \\
\hline$\rho$ & 0.020 & {$[0.012,0.028]$} & 0.023 & {$[0.016,0.029]$} \\
\hline$\eta$ & 0.93 & {$[0.88,0.99]$} & 0.93 & {$[0.89,0.98]$} \\
\hline $\bar{r}$ & 0.045 & {$[0.024,0.064]$} & 0.008 & {$[0.001,0.016]$} \\
\hline$\rho_{R}$ & 0.75 & {$[0.63,0.88]$} & 0.93 & {$[0.89,0.97]$} \\
\hline$\lambda$ & 0.50 & {$[0.17,0.80]$} & 1.39 & {$[1.04,1.70]$} \\
\hline$\mu$ & 0.85 & {$[0.52,1.18]$} & 0.64 & {$[0.34,0.92]$} \\
\hline$\rho_{d}$ & 0.78 & {$[0.71,0.85]$} & 0.63 & {$[0.55,0.71]$} \\
\hline$\rho_{s}$ & 0.90 & {$[0.84,0.97]$} & 0.94 & {$[0.91,0.98]$} \\
\hline$\sigma_{R}$ & 0.004 & {$[0.004,0.005]$} & 0.006 & {$[0.005,0.006]$} \\
\hline$\sigma_{d}$ & 0.008 & {$[0.006,0.009]$} & 0.007 & {$[0.005,0.009]$} \\
\hline$\sigma_{s}$ & 0.022 & {$[0.008,0.038]$} & 0.011 & {$[0.008,0.014]$} \\
\hline$\sigma_{\zeta}$ & 0.005 & {$[0.004,0.006]$} & $\mathrm{n} / \mathrm{a}$ & $\mathrm{n} / \mathrm{a}$ \\
\hline$\rho_{R d}$ & -0.47 & {$[-0.67,-0.27]$} & 0.27 & {$[0.10,0.45]$} \\
\hline$\rho_{R s}$ & 0.88 & {$[0.77,0.99]$} & 0.20 & {$[0.01,0.40]$} \\
\hline$\rho_{d s}$ & -0.62 & {$[-0.89,-0.34]$} & 0.70 & {$[0.56,0.85]$} \\
\hline$\beta$ & $\mathrm{n} / \mathrm{a}$ & $\mathrm{n} / \mathrm{a}$ & 0.97 & {$[0.95,0.99]$} \\
\hline$\phi$ & $\mathrm{n} / \mathrm{a}$ & $\mathrm{n} / \mathrm{a}$ & 0.26 & {$[0.11,0.41]$} \\
\hline
\end{tabular}

We find differences in the policy parameters $\bar{r}$, and $\mu$ and large significant differences in $\lambda$, and $\rho_{R}$. In line with previous studies (Primiceri, 2005; Sims and Zha, 2006), we find that the estimated volatility of the shocks dropped significantly after the Volcker disinflation.

In Section VIII we provide further insights on the role that these changes played in affecting the relationship between inflation rate, output gap and nominal interest rate.

\section{What Changed in 1980 ?}

There is a large literature that asks: Why do the data look different after the Volcker disinflation? At least two answers have been given to that question. One answer, favored by Sims and Zha (2002), is that the primary reason for a change in the behavior of the data before and after the Volcker disinflation is that the variance of the driving shocks was larger in the pre-Volcker period. Primiceri (2005) finds some evidence that policy also changed but his structural VAR is unable to disentangle changes in the policy rule from changes in the private sector equations.

Previous work by Canova and Gambetti (2004) explains the reduction in volatility after 1980 as a consequence of better monetary policy. But when Lubik and Schorfheide (2004) estimate a NK model over two separate sub-periods they find 
significant difference across regimes, not only in the policy parameters, but also in their estimates of the private sector parameters. That leads to the following question. Can the FM model explain the change in the behavior of the data before and after 1980 in terms of a change only in the policy parameters? To answer that question, we estimated five alternative models. The results are reported in Table 5 .

In Model 1, Fully unrestricted, we estimated all the parameters of the FM model separately for the two sub-periods. In Model 2, Policy and shocks, we allowed the variances of the shocks and the parameters of the policy rule to change across sub-periods, but we constrained the parameters of the IS curve to be the same. In Models 3, Shocks only, we allowed only the variances of the shocks to change and in Model 4, we allowed only the Policy Rule parameters to change. Finally, in Model 5, we restricted all of the parameters to be the same in both sub-periods.

\begin{tabular}{lcc}
\hline \multicolumn{2}{c}{ Table 5: Model specifications } \\
\hline & Log data density & Posterior model prob \\
\hline Fully unrestricted & 2159.48 & - \\
Policy and shocks & 2159.39 & $47.7 \%$ \\
Shocks only & 2141.56 & $0 \%$ \\
Policy only & 2121.42 & $0 \%$ \\
Fully restricted & 2113.25 & $0 \%$ \\
\hline
\end{tabular}

The results in Table 5 indicate that the specification in which policy parameters and shocks are allowed to differ explains the data almost as well as the fully unrestricted model specification. But as soon as we restrict either the policy parameters or the shocks to be the same, the explanatory power of the FM model drops substantially. With the exception of Model 2, Policy and shocks, all of the restrictions are clearly rejected.

Why was the post-Volcker regime relatively benign? In line with previous studies, we find that both good policy and good luck had a part to play. The postVolcker period, leading up to the Great Recession, was associated with fewer large shocks and with no large negative supply shocks of the same order of magnitude as the oil price shocks of 1973 and 1978. It was also associated with a change in the policy rule followed by the Fed. What we add to previous studies is a model in which our estimates of the structural private sector parameters remain invariant across both regimes. The Fed changed its behavior; households did not. 


\section{Conclusions}

The FM model gives a very different explanation of the relationship between inflation, the output gap and the federal funds rate from the conventional NK approach. It is a model where demand and supply shocks may have permanent effects on employment and inflation and our empirical findings demonstrate that this model fits the data better than the NK alternative. The improved empirical performance of the FM model stems from its ability to account for persistent movements in the data.

In the FM model, beliefs about nominal income growth are fundamentals of the economy. Beliefs select the equilibrium that prevails in the long-run and monetary policy chooses to allocate shocks to permanent changes in inflation expectations or permanent deviations of output from its trend growth path.

Our findings have implications for the theory and practice of monetary policy. Central bankers use the concept of a time-varying natural rate of unemployment before deciding when and if to raise the nominal interest rate. The difficulty of estimating the natural rate arises, in practice, because the economy displays no tendency to return to its natural rate. That fact has led to much recent skepticism about the usefulness of the Phillips curve in policy analysis. Although we are sympathetic to the Keynesian idea that aggregate demand determines employment, we have shown in this paper that it is possible to construct a 'Keynesian economics' without the Phillips curve. 


\section{REFERENCES}

Stéphane Adjemian, Houtan Bastani, Michel Juillard, Junior Maih, Fréderic Karamé, Ferhat Mihoubi, George Perendia, Johannes Pfeifer, Marco Ratto, and Sébastien Villemot. Dynare: Reference manual version 4. Dynare Working Papers, CEPREMAP, 1, 2011.

Andreas Beyer and Roger E. A. Farmer. On the indeterminacy of new-keynesian economics. European Central Bank Working Paper Series, No. 323, (323), 2004.

Andreas Beyer and Roger E. A. Farmer. Natural rate doubts. Journal of Economic Dynamics and Control, 31(121):797-825, 2007.

Olivier J. Blanchard and Lawrence H. Summers. Hysteresis and the european unemployment problem. In Stanley Fischer, editor, NBER Macroeconomics Annual, volume 1, pages 15-90. National Bureau of Economic Research, Boston, MA, 1986.

Olivier J. Blanchard and Lawrence H. Summers. Hysteresis in unemployment. European Economic Review, 31:288-295, 1987.

Fabio Canova and Luca Gambetti. Bad luck or bad policy? on the time variations of us monetary policy. Manuscript, IGIER and Universítá Bocconi, 2004.

Lawrence Christiano, Martin Eichenbaum, and Charles Evans. Nominal rigidities and the dynamics effects of a shock to monetary policy. Journal of Political Economy, 113:1-45, 2005.

Richard Clarida, Jordi Galí, and Mark Gertler. The science of monetary policy: A new keynesian perspective. Journal of Economic Literature, 37(December): 1661-1707, 1999.

Richard Clarida, Jordi Galí, and Mark Gertler. Monetary policy rules and macroeconomic stability: Evidence and some theory. Quarterly Journal of Economics, 115(1):147-180, 2000.

Diego Comin and Mark Gertler. Medium term business cycles. American Economics Association, 96(3):526-531, 2006.

Gauti B. Eggertsson and Neil R. Mehrotra. A model of secular stagnation. NBER Working Paper 20574, 2014.

Robert J. Engle and Clive W. J. Granger. Cointegration and error correction: representation, estimation and testing. Econometrica, 55:251-276, 1987.

Roger E. A. Farmer. The Macroeconomics of Self-Fulfilling Prophecies. MIT Press, Cambridge, MA, 1993. 
Roger E. A. Farmer. Confidence, crashes and animal spirits. Economic Journal, 122(559), March 2012a.

Roger E. A. Farmer. Animal spirits, persistent unemployment and the belief function. In Roman Frydman and Edmund S. Phelps, editors, Rethinking Expectations: The Way Forward for Macroeconomics, chapter 5, pages 251-276. Princeton University Press, Princeton, NJ, 2012b.

Roger E. A. Farmer. The stock market crash really did cause the great recession. NBER Working Paper 19391 and CEPR Discussion Paper 9630, 2013.

Roger E. A. Farmer. Pricing assets in an economy with two types of people. NBER Working Paper 22228, 2016.

Roger E. A. Farmer and Konstantin Platonov. Animal spirits in a monetary model. NBER Working Paper 22136, 2016.

Roger E. A. Farmer, Vadim Khramov, and Giovanni Nicoló. Solving and estimating indeterminate dsge models. Journal of Economic Dynamics and Control., 54:17-36, 2015.

Jordi Galí. Monetary Policy, Inflation, and the Business Cycle: An Introduction to the New Keynesian Framework. Princeton University Press, 2008.

Felix R. Gantmacher. Matrix Theory, volume II. AMS Chelsea Publishing, Providence Rhode Island, 2000.

John Geweke. Using simulation methods for bayesian econometric models: Inference, development, and communication. Econometric Reviews, 18(1):1-73, 1999.

Robert J. Gordon. The phillips curve is alive and well: Inflation and the nairu during the slow recovery. NBER WP 19390, 2013.

Alvin Hansen. Economic progress and declining population growth. American Economic Review, 29(1):1-15, 1939.

Robert G. King and Mark W. Watson. The post-war u.s. phillips curve: A revisionist econometric history. Carnegie-Rochester Conference Series on Public Policy, 41:157-219, 1994.

Robert G. King, Charles I. Plosser, James H. Stock, and Mark W. Watson. Stochastic trends and economic fluctuations. American Economic Review, 81 (4):819-840, 1991.

Peter J. Klenow and Benjamin A. Malin. Microeconomic evidence on price setting. Prepared for the Handbook of Monetary Economics, 2010.

Thomas A. Lubik and Frank Schorfheide. Testing for indeterminacy: An application to u.s. monetary policy. American Economic Review, 94:190-219, 2004. 
Gregory N. Mankiw. Small menu costs and large buiness cycles: A macroeconomic model of monopoly. QJE, 100:529-537, 1985.

N. Gregory Mankiw. Principles of Economics. Cengage, New York, 2015. Seventh Edition.

N. Gregory Mankiw and Ricardo Reis. Sticky information in general equilibrium. Journal of the European Economic Association, 5(2-3):603-613, 2007.

Charles R Nelson and Charles I Plosser. Trends and random walks in macroeconomic time series. Journal of Monetary Economics, 10:139-162, 1982.

Federal Reserve Bank of San Francisco. Stimulus arithmetic (wonkish but important). Education: How did the Fed change its approach to monetary policy in the late 1970s and early 1980s?, Jaunuary January 2003. URL http://www.frbsf.org/education/publications/doctor-econ/2003/ january/monetary-policy-1970s-1980s/.

Dmitry Plotnikov. Hysterisis in unemployment and jobless recoveries. mimeo, UCLA, 2012.

Dmitry Plotnikov. Three Essays on Macroeonomics with Incomplete Factor Markets. PhD thesis, UCLA, 2013.

Giorgio Primiceri. Time varying structural vector autoregressions and monetary policy. Review of Economic Studies, 72:821-852, 2005.

Christopher A. Sims. Macroeconomics and reality. Econometrica, 48(January): $1-48,1980$.

Christopher A. Sims. Implications of rational inattention, 2001a. Mimeo, Princeton University.

Christopher A. Sims. Solving linear rational expectations models. Journal of Computational Economics, 20(1-2):1-20, 2001b.

Christopher A. Sims and Tao Zha. Macroeconomic switching, 2002. Mimeo, Princeton University.

Christopher A. Sims and Tao Zha. Were there regime switches in us monetary policy? The American Economic Review, 96(1):54-81, 2006.

Frank Smets and Raf Wouters. Shocks and frictions in U.S. business cycles: A Bayesian DSGE approach. American Economic Review, 97(3):586-606, June 2007.

Lawrence H Summers. U.S. economic prospects: Secular stagnation, hysteresis, and the zero lower bound. Business Economics, 49(2):65-73, 2014. 
John B. Taylor. An historical analysis of monetary policy rules. In John B. Taylor, editor, Monetary Policy Rules, pages 319-341. University of Chicago Press, Chicago, 1999.

Michael Woodford. Interest and Prices: Foundations of a Theory of Monetary Policy. Princeton University Press, Princeton, N.J., 2003. 
Appendix A: The Reduced Forms of the NK and FM Models

In Appendix A we find solutions to simplified versions of the two models and we show how they are different from each other. To find closed form solutions, we set $\rho=0, \eta=0, a=1, \bar{r}=0$ and $\rho_{R}=0$. These simplifications allow us to solve the models by hand using a Jordan decomposition. For more general parameter values we rely on numerical solutions that we compute using Christopher Sim's code, GENSYS Sims (2001b).

\section{A1. Solving the NK Model}

Consider the following stripped down version of the NK model

$$
\begin{aligned}
y_{t} & =E_{t}\left[y_{t+1}\right]-\left(R_{t}-E_{t}\left[\pi_{t+1}\right]\right) \\
R_{t} & =\lambda \pi_{t}+\mu y_{y}+z_{R, t} \\
\pi_{t} & =\beta E_{t-1}\left(\pi_{t+1}\right)+\phi y_{t} \\
\eta_{1, t} & =y_{t}-E_{t-1}\left(y_{t}\right) \\
\eta_{2, t} & =\pi_{t}-E_{t-1}\left(\pi_{t}\right)
\end{aligned}
$$

The model can be written in the following matrix form

$$
\Gamma_{0} X_{t}=\Gamma_{1} X_{t-1}+\Psi \varepsilon_{t}+\Pi \eta_{t}
$$

where $X_{t} \equiv\left(y_{t}, \pi_{t}, E_{t}\left(y_{t+1}\right), E_{t}\left(\pi_{t+1}\right)\right)^{\top}, \varepsilon_{t}=\left(z_{R, t}\right)$ and $\eta_{t}=\left(\eta_{1, t}, \eta_{2, t}\right)^{\top}$.

Defining the matrix $\Gamma_{1}^{*} \equiv \Gamma_{0}^{-1} \Gamma_{1}$ we may rewrite this equation,

$$
X_{t}=\Gamma_{1}^{*} X_{t-1}+\Psi^{*} \varepsilon_{t}+\Pi^{*} \eta_{t}
$$

The existence of a unique bounded solution to Equation (A2) requires that two roots of the matrix $\Gamma_{1}^{*}$ are outside the unit circle. This condition is satisfied when the following generalized form of the Taylor Pricipal holds,

$$
\left|\lambda+\frac{1-\beta}{\phi} \mu\right|>1 \text {. }
$$

In this case, the reduced form is an equation,

$$
X_{t}=G^{N K} X_{t-1}+H^{N K} z_{R, t}
$$

where $H^{N K}$ is a $5 \times 1$ vector of coefficients and $G^{N K}$ is a $5 \times 5$ matrix of zeros.

When the Taylor Principle breaks down, one or more elements of the vector of non-fundamental shocks, $\eta_{t}$, can be reclassified as fundamental. In that case, the 
reduced form can be represented as

$$
X_{t}=G^{N K} X_{t-1}+H^{N K}\left[\begin{array}{c}
z_{R, t} \\
\eta_{1, t}
\end{array}\right]
$$

where $H^{N K}$ is a $5 \times 2$ vector of coefficients and $G^{N K}$ is a $5 \times 5$ matrix of rank 4 .

\section{A2. Solving the FM model}

The equivalent stripped-down version of the FM model is represented by the equations,

$$
\begin{aligned}
y_{t} & =\mathbb{E}_{t}\left[y_{t+1}\right]-\left(R_{t}-\mathbb{E}_{t}\left[\pi_{t+1}\right]\right), \\
R_{t} & =\lambda \pi_{t}+\mu y_{t}+z_{R, t}, \\
x_{t} & =\mathbb{E}_{t}\left[x_{t+1}\right], \\
x_{t} & =y_{t}-y_{t-1}+\pi_{t}, \\
\eta_{t} & =x_{t}-E_{t-1}\left(x_{t}\right) .
\end{aligned}
$$

Using the definition of $x_{t}$ and the Taylor Rule to eliminate $\pi_{t}$ and $R_{t}$. this can be rewritten as a system of three equations in the variables $x_{t}, y_{t}$ and $\mathbb{E}_{t}\left[x_{t+1}\right]$,

$$
\begin{aligned}
\mathbb{E}_{t}\left[x_{t+1}\right]-\lambda x_{t}-(\mu-\lambda) y_{t} & =\lambda y_{t-1}+z_{R, t} \\
\mathbb{E}_{t}\left[x_{t+1}\right]-x_{t} & =0 \\
x_{t} & =E_{t-1}\left(x_{t}\right)+\eta_{t} .
\end{aligned}
$$

In matrix notation

$$
\Gamma_{0} X_{t}=\Gamma_{1} X_{t-1}+\Psi \varepsilon_{t}+\Pi \eta_{t},
$$

where $X_{t} \equiv\left(\mathbb{E}_{t}\left[x_{t+1}\right], x_{t}, y_{t}\right), \varepsilon_{t}=\left(z_{R, t}\right)^{\top}$ and

$$
\Gamma_{0}=\left[\begin{array}{ccc}
1 & \lambda & \lambda-\mu \\
1 & -1 & 0 \\
0 & 1 & 0
\end{array}\right], \quad \Gamma_{1}=\left[\begin{array}{ccc}
0 & 0 & \lambda \\
0 & 0 & 0 \\
1 & 0 & 0
\end{array}\right], \quad \Psi=\left[\begin{array}{l}
1 \\
0 \\
0
\end{array}\right] \quad \Pi=\left[\begin{array}{l}
0 \\
0 \\
1
\end{array}\right]
$$

For this example the matrix $\Gamma_{0}$ is non-singular and the system can be written as

$$
X_{t}=\Gamma_{1}^{*} X_{t-1}+\Psi^{*} \varepsilon_{t}+\Pi^{*} \eta_{t}
$$

where $\Gamma_{1}^{*} \equiv \Gamma_{0}^{-1} \Gamma_{1}, \Psi^{*} \equiv \Gamma_{0}^{-1} \Psi$ and $\Pi^{*} \equiv \Gamma_{0}^{-1} \Pi$. 
The matrix $\Gamma_{1}^{*}$ is given by the expression

$$
\Gamma_{1}^{*}=\left[\begin{array}{ccc}
1 & 0 & 0 \\
1 & 0 & 0 \\
-\frac{1+\lambda}{\lambda-\mu} & 0 & \frac{\lambda}{\lambda-\mu}
\end{array}\right]
$$

which has eigenvalues $\left\{0,1, \frac{\lambda}{\lambda-\mu}\right\}$. Since the model has one non-fundamental shock, $\eta_{t}$, the analog of the Taylor Principle requires one root of $\Gamma_{1}^{*}$ to lie outside the unit circle, that is

$$
\left|\frac{\lambda}{\lambda-\mu}\right|>1 \text {. }
$$

When the Taylor Principle holds, the reduced form is an equation of the form

$$
X_{t}=G^{F M} X_{t-1}+H^{F M} z_{R, t}
$$

where $G^{F M}$ is constructed by choosing $\eta_{t}$ to eliminate the unstable root. The resulting matrix, $G^{F M}$ two zero roots and a root of unity.

\section{Appendix B: Dynamic Properties for Generalized IS Curve}

We now show that the dynamic properties of the FM model depend not only on the parameters of the monetary policy reaction function but importantly also on the parameter of relative risk aversion $a$. To simplify the notation, we consider the case of $\rho_{R}=0$ and proceed to solve the model as in Appendix A. The roots of the system are $\lambda_{1}=\lambda_{2}=0, \lambda_{3}=1$ and

$$
\lambda_{4,5}=\frac{-(\lambda-\mu-a+1) \pm \sqrt{(\lambda-\mu-a+1)^{2}+4 \lambda(a-1)}}{2(a-1)} .
$$

Given the posterior mean of the parameter $\lambda=0.92$ and $\mu=0.99$, we focus on the approximated roots for $(\lambda-\mu)=0$. Thus, we obtain

$$
\lambda_{4,5}=\frac{(a-1) \pm \sqrt{(-a+1)^{2}+4 \lambda(a-1)}}{2(a-1)}=\frac{1}{2} \pm \frac{1}{2} \sqrt{1+\frac{4 \lambda}{(a-1)}} .
$$

We first show that the eigenvalue $\lambda_{4}=\frac{1}{2}+\frac{1}{2} \sqrt{1+\frac{4 \lambda}{(a-1)}}$ is always unstable for realistic values of the parameter $\lambda$ and $a$. If $(a-1)>0$, then $\lambda_{4}>1$. If $(a-1)<0$, then $0<\lambda_{4}<1$ if and only if $4 \lambda<(1-a)$ or equivalently $a<1-4 \lambda$. For realistic values of the parameter $\lambda$, this is never the case, implying that $\lambda_{4}$ is always an unstable root of the model.

Given that the FM model has two forward-looking variables and that $\lambda_{4}>1$, the model is dynamically determinate if $\lambda_{5}=\left[\frac{1}{2}-\frac{1}{2} \sqrt{1+\frac{4 \lambda}{(a-1)}}\right]<-1$. Simpli- 
fying, this condition can be written as

$$
a<1+\frac{\lambda}{2}
$$

The posterior means reported in Table 3 and 4 for both the pre- and postVolcker period indicate that this condition is violated, and that the dynamic properties of the FM model crucially depend on the value of the parameter $a$. 